\title{
Artritis idiopática de muñeca en una niña de 4 años de edad
}

\author{
M. García-Elías CoS $^{(1)}$, F. Romero Prieto ${ }^{(2)}$ \\ INSTITUTO KAPLAN \\ (1) Doctor en Medicina, Especialista en Cirugía de la Mano. Miembro del Instituto Kaplan

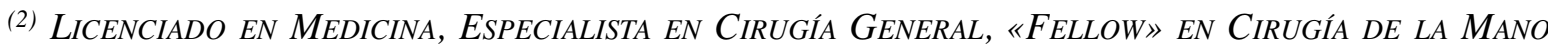 \\ DEL INSTITUTO KAPLAN Y DE LA UB
}

Correspondencia:

Dr. Marc García-Elías Cos

Instituto Kaplan

Paseo de la Bonanova, 9, $2^{\circ} 2^{\mathrm{a}}$

08022 Barcelona

Teléf: 934178484

Fax: 932110402

e-mail: garciaelias@infonegocio.com

\begin{abstract}
Se presenta un caso de artritis idiopática de muñeca en una niña de 4 años que causó una grave desaxación carpiana en VISI con subluxación palmar de la articulación mediocarpiana. Fue tratada quirúrgicamente mediante una sinovectomía más reducción y fijación percutánea con una aguja de Kirschner con un resultado excelente que se mantiene a las 58 semanas de la intervención. Tanto la biopsia sinovial como los patrones analíticos descartaron la enfermedad reumatoide.
\end{abstract}

Palabras clave: artritis muñeca, idiopática, inestabilidad en VISI, sinovectomia.
A case of an idiopathic arthritis of the wrist in a 4 year old girl, causing severe VISI pattern of carpal malalignment with palmar subluxation of the midcarpal joint is presented. Surgical treatment, consisting on synovectomy plus reduction and Kirschner wire percutaneous fixation, resulted in an excellent outcome which has been maintained for 58 weeks. Both synovial biopsy and blood tests were negative for rheumatoid arthritis.

Key words: Wrist arthritis, idiopathic, VISI pattern of instability, synovectomy.

Rev. Iberam. Cir. Mano - Vol. 36 - Núm. 1 Mayo 2008 (31-34)

\section{INTRODUCCIÓN}

L a artritis de muñeca en los primeros años de la vida es una entidad muy poco frecuente. Según recientes estudios existe una prevalencia anual de 113.4 en 100.000 niños en USA y 86.3 por 100.000 niños en Europa, la mayoría en forma de «Artritis Idiopática Juvenil» (AIJ), término acuñado por la Liga Internacional contra el reumatismo en substitución de los términos «Artritis Reuma- toide Juvenil»o «Artritis Crónica Juvenil»1, 2 . Se presenta un caso de AIJ donde el fenómeno inflamatorio agudo no pasó a forma crónica ni aparecieron patrones analíticos propios de una enfermedad reumatoide.

\section{CASO CLÍNICO}

Niña de 4 años y 7 meses de edad, sin ningún antecedente traumático conocido, que su- 


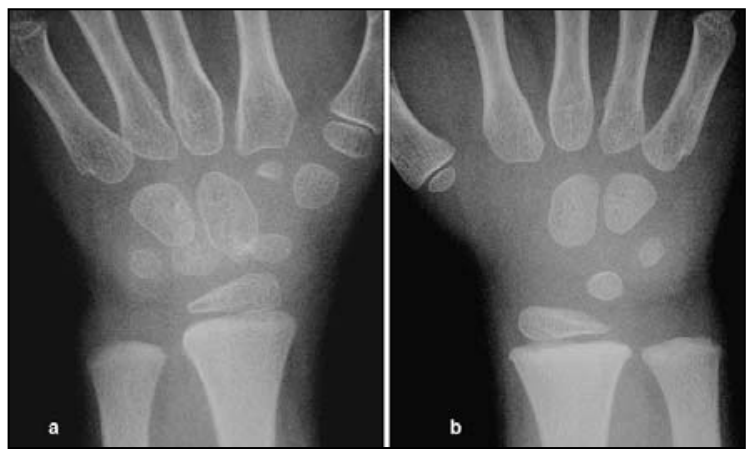

Figura 1: a) Aspecto radiológico de la muñeca izquierda. Desarrollo óseo de los huesos carpianos anormalmente evolucionado en comparación (b) con el lado derecho.

frió un episodio de dolor y tumefacción de su muñeca izquierda, aparecido espontáneamente dos meses antes de ser visitada en noviembre de 2002. No tuvo nunca fiebre. Durante el brote la niña había sido tratada con antiinflamatorios no esteroideos, que disminuyeron el dolor y la tumefacción; no obstante la movilidad no se recuperó, motivo por el cual nos fue derivada para estudio y tratamiento.

El examen físico evidenció una limitación indolora de la movilidad pasiva de la muñeca izquierda (flexión: $45^{\circ}$, extensión: $40^{\circ}$ ). El resto de la exploración era anodina.

Radiológicamente, se observó un desarrollo anormalmente evolucionado de los huesos car- pianos en comparación con los del lado sano (Figura 1). Existía una subluxación palmar de la hilera distal respecto al semilunar y escafoides, los cuales estaban anormalmente flexionados respecto al radio (colapso carpiano en VISI). El ángulo radiolunar era de $75^{\circ}$ hacia palmar (Figura 2).

A fin de reducir la desaxación carpiana y obtener muestras artrosinoviales para su posterior análisis, se decidió intervenirla quirúrgicamente. Se abordó la cápsula radiocarpiana desinsertándola proximalmente del radio, momento en el cual pudo observarse la presencia de abundante sinovitis articular que se extirpó y se analizó histológicamente (Figura 3a). La incisión capsular se extendió distalmente a fin de exponer los espacios articulares radiocarpiano y mediocarpiano (Figura 3b). Con ello se pudo objetivar la presencia de una fila proximal del carpo anormalmente flexionada, si bien con integridad de los ligamentos interóseos escafolunar y lunopiramidal. Dicha subluxación se reducía muy fácilmente mediante tracción longitudinal de los dedos y compresión dorsopalmar del semilunar hacia su posición normal sobre el radio. Tras una sinovectomia articular minuciosa, se procedió a la reducción y estabilización de la articulación mediocarpiana mediante una aguja Kirschner
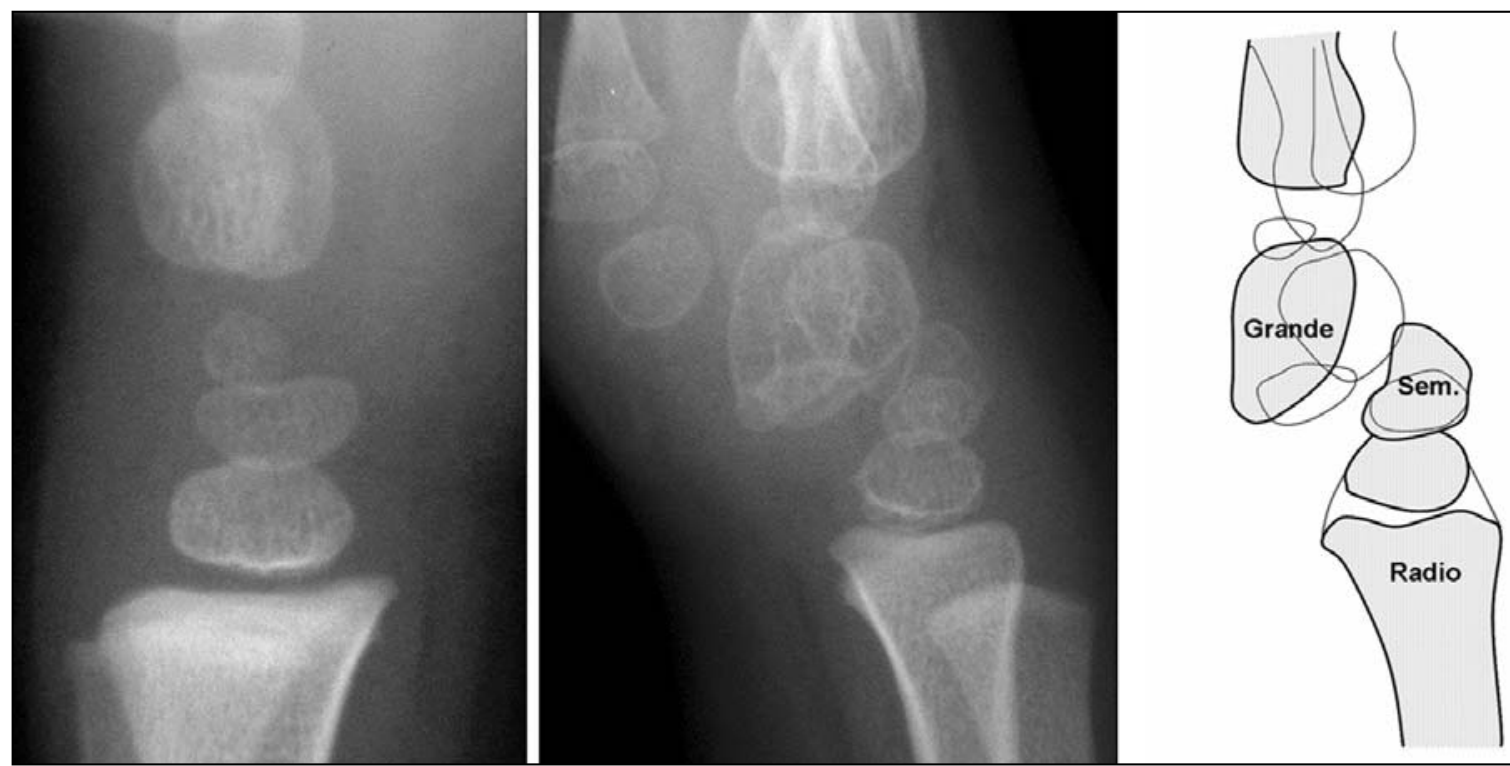

Figura 2: Subluxación palmar de la hilera proximal respecto al semilunar y escafoides, que están anormalmente flexionados (colapso carpiano en VISI). Ángulo radiolunar: $75^{\circ}$ palmar. 

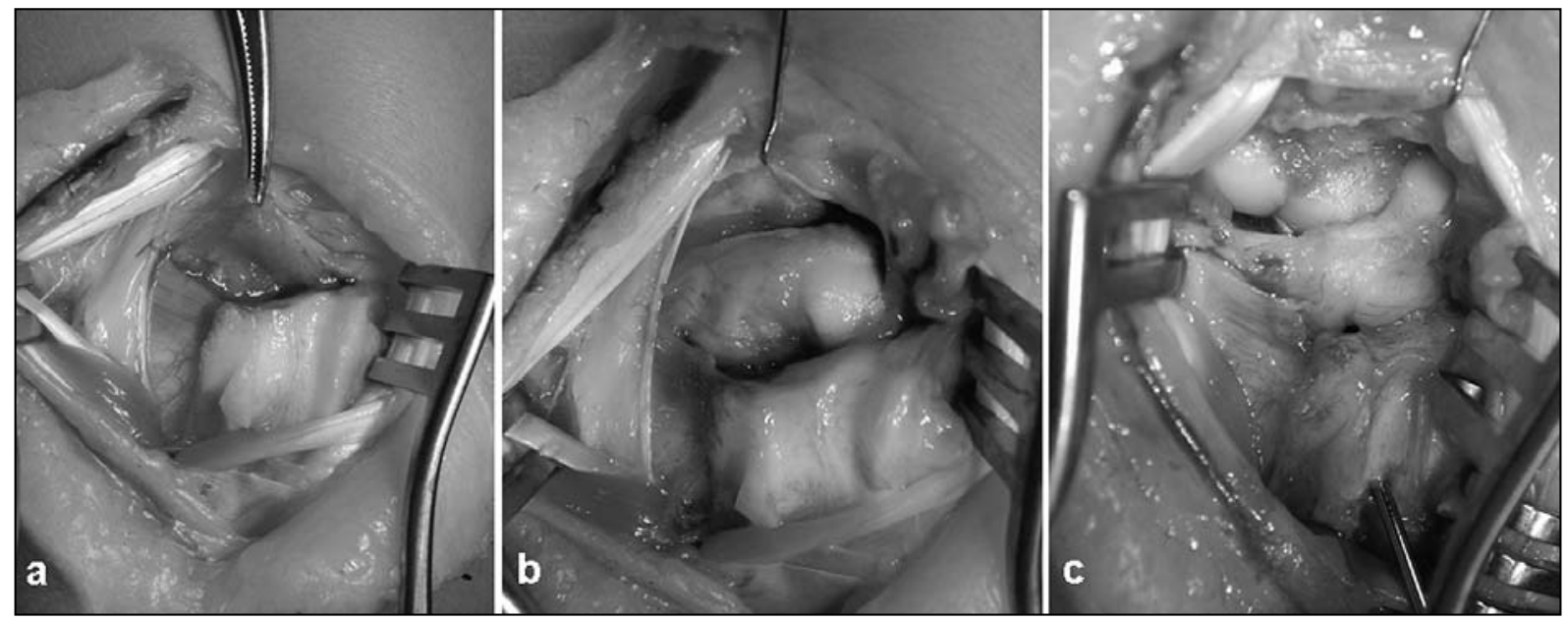

Figura 3: Imágenes obtenidas durante la intervención quirúrgica realizada en Diciembre del 2002. a) desinserción capsular proximal demostrando la presencia de sinovitis articular que se extirpa y analiza histológicamente (sinovitis inespecífica, sin granulomas) y bacteriológicamente (no infección). b) aspecto articular tras capsulotomía más amplia: la fila proximal del carpo se halla anormalmente flexionada, mientras que la distal está subluxada hacia la palma. c) reducción relativamente sencilla, que se estabiliza mediante una aguja Kirschner de $1.2 \mathrm{~mm}$ que penetra el borde dorsal de la epífisis del radio, pasando por el espacio escafolunar hasta penetrar en el polo proximal del ganchoso.

de $1.2 \mathrm{~mm}$ penetrando por la cara dorsal de la epífisis del radio (distal a la fisis), pasando por el espacio escafolunar hasta penetrar en el polo proximal del ganchoso (intentando evitar perforar zonas de carga) (Figura 3c). La aguja se retiró a las 4 semanas si bien la muñeca se mantuvo inmovilizada durante 6 semanas en un yeso antebraquial.

El análisis anatomopatológico de la sinovial obtenida no descubrió cual fue la causa inicial de la artritis, etiquetando el caso como el de una sinovitis subaguda inespecífica, sin granulomas ni la presencia de depósitos de microcristales.

A los 5 meses de la intervención, y a pesar de la rehabilitación funcional, la movilidad global de la articulación seguía reducida, si bien no existía dolor ni una limitación funcional destacable. Los controles radiológicos en aquel momento mostraron la pérdida parcial de la alineación carpiana con una subluxación palmar mediocarpiana y un ángulo radiolunar de $42^{\circ}$ hacia palmar. Dado que la paciente estaba asintomática, se decidió no plantear una nueva intervención y seguir con los controles periódicos.

En septiembre del 2007, a los 4 años y 10 meses de la intervención y cuando la paciente había cumplido ya los 9 años de edad, se tuvo la ocasión de evaluarla de nuevo. Sorprenden- temente, la niña había evolucionado mucho mejor de lo previsto, con un rango articular casi normal (déficit de tan sólo $15^{\circ}$ de extensión y flexión pasivas), sin dolor y permitiéndole participar activamente en todas las actividades físicas propias de su edad. Radiológicamente destaca un semilunar levemente aplanado en su mitad palmar, bien vascularizado y con una correcta trabeculación interna, un hueso grande ligeramente subluxado anteriormente, y un escafoides en una posición de relativa subluxación proximodorsal. La altura carpiana se halla ligeramente reducida respecto al lado contralateral, si bien todo ello en un contexto de remodelación articular muy notable (Figura 4).

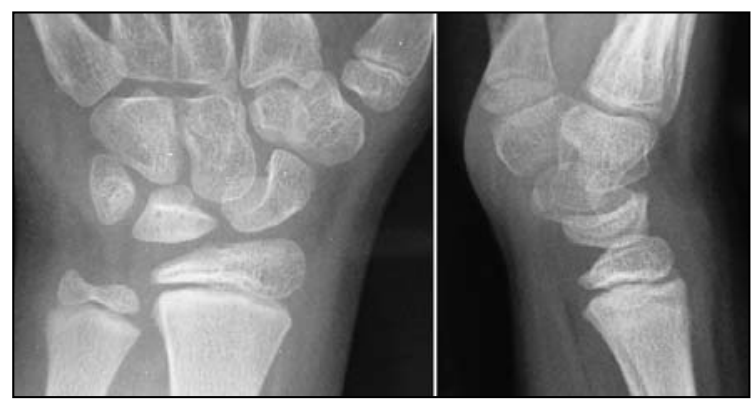

Figura 4: Aspecto radiológico a los 4 años y 10 meses de la intervención. Ligeros cambios en la forma del semilunar, y tendencia al VISI (ángulo radiolunar: $20^{\circ}$ palmar). Desarrollo óseo casi simétrico en relación al lado contralateral. 


\section{DISCUSIÓN}

Según la reciente clasificación de Laxer y Clarke $^{1}$, la paciente puede enmarcarse dentro del grupo de las artritis oligoarticulares del tipo 1 , es decir, el grupo de las artritis persistentes, de inicio temprano, afectando a menos de cuatro articulaciones, y con una mayor incidencia en el sexo femenino. Según dichos autores, la muñeca aparece afectada en un $12 \%$ de dichos pacientes. En dichos casos la mano suele presentar una cierta tumefacción dorsal con pérdida variable de la extensión de muñeca, hipersensibilidad en el área afectada, dolor a la flexión y extensión pasiva, y una restricción para la utilización de los músculos del antebrazo y mano que pueden hacer sospechar erróneamente una lesión neurológica.

El desarrollo óseo asimétrico no es patognomónico de este tipo de artritis, sino que puede encontrarse en cualquiera patología que suponga un aumento significativo y prolongado de la vascularización regional. En este caso ello fue debido a un proceso inflamatorio crónico de origen desconocido, y que afortunadamente resultó ser casi reversible con el paso del tiempo. En otras circunstancias menos afortunadas, la deformidad ósea suele ser permanente, o incluso evolucionar hacia una marcada translocación cubital e inestabilidad progresiva de la articulación radiocubital distal ${ }^{2}$.

Una de las más temibles complicaciones que pueden aparecer en la artritis idiopática juvenil tipo 1 , y que por fortuna no hemos observado en nuestra paciente, es la aparición iridociclitis, glaucoma, e incluso ceguera. Se trata de una asociación frecuente (entre un $20 \%$ y un $50 \%$ de los pacientes) de naturaleza etiopatogénica desconocida. Es muy importante, por tanto, mantener controles oftalmológicos periódicos de estos pacientes durante toda la adolescencia y durante la edad adulta, a fin de que si esta complicación aparece, pueda ser tratada de forma precoz.

En la literatura solo hemos encontrado un caso con una radiología parecida a la de nuestra paciente, y que fue publicado en 1999 por Graham y Jacobson ${ }^{3}$. Se trataba de un adolescente con un problema neurológico crónico que le causaba una hemiatrofia muscular que desencadenó un progresivo colapso carpiano en VISI (luxación mediocarpiana) que fue tratado mediante artrodesis total. Obviamente, no podemos comparar nuestros resultados con los de aquel caso, puesto que en aquel existió una explicación biomecánica razonable del porqué se descompensó la muñeca. En nuestro caso, creemos que la descompensación no fue debida un factor extraarticular como el publicado por Graham y Jacobson, sino a un factor intraarticular, una sinovitis aséptica transitoria que afectó y distendió los dos grupos ligamentosos palmares (piramidal-ganchosogrande y escafoides-trapecio-trapezoide) que aseguran la estabilidad mediocarpiana evitando el colapso mediocarpiano en VISI.

Si bien la sinovectomía quirúrgica más realineación carpiana, como sugieren Kvien et al. ${ }^{4}$, fue beneficiosa en este caso, desconocemos si no hubiéramos llegado al mismo resultado con un tratamiento rehabilitador, según preconizan Barden et al..$^{5}$. No obstante, y dada la escasez de experiencia clínica publicada en la literatura, creemos que este tipo de cirugía no perjudica a la paciente sino, al contrario, limita el daño articular que podía haber causado una sinovitis prolongada.

\section{BIBLIOGRAFÍA}

1. Laxer RM, Clarke HM. Rheumatic disorders of the hand and wrist in childhood and adolescence. Hand Clinics, 2002; 16: 659-71.

2. Evans DM, Ansell BM, Hall MA. The wrist in juvenile arthritis. J Hand Surg Br, 1991; 16: 293304.
3. Graham TJ, Jacobson PA. Atraumatic palmar midcarpal dislocation in a skeletally immature adolescent with hemiatrophy. J Hand Surg Am, 1999; 24: 1281-5.

4. Kvien TK, Pahle JA, Hoyeraal HM, Sandstadt B. Comparison of synovectomy and no syno- vectomy in patients with juvenile rheumatoid arthritis. A 24 month controlled study. Scand J Rheum, 1987; 16: 81-91.

5. Barden W, Brooks D, AylingCampos A. Physical therapy management of the subluxated wrist in children with arthritis. Phys Ther, 1995; 75: 879-85. 